Abstract

\title{
The Cocoon System: Ecotechnology for Ecological Restoration and Rainfed Agriculture in the Mediterranean Basin ${ }^{+}$
}

\author{
Vicenç Carabassa ${ }^{1,3, *}$, Ander Achotegui-Castells ${ }^{2}$, Xavier Domene ${ }^{1,3}$ and Josep Maria Alcañiz ${ }^{1,3}$ \\ 1 CREAF, E08193 Bellaterra (Cerdanyola del Vallès), Catalonia, Spain; x.domene@creaf.uab.cat (X.D.); \\ josemaria.alcaniz@uab.cat (J.M.A.) \\ 2 Fundació Emys, Carretera de Santa Coloma km 21.1, 17421 Riudarenes, Catalonia, Spain; \\ ander@funacioemys.org \\ 3 Universitat Autònoma de Barcelona, E08193 Bellaterra (Cerdanyola del Vallès), Catalonia, Spain \\ * Correspondence: v.carabassa@creaf.uab.cat \\ + Presented at TERRAenVISION 2019, Barcelona, Spain, 2-7 September 2019.
}

Published: 20 December 2019

\begin{abstract}
Ecological restoration projects of degraded natural areas or rainfed agriculture in the Mediterranean region, especially when they include the plantation of woody species, generally shown to be very expensive and inefficient, mainly due to the large number of leaks during the first summer drought. Even in cases where support irrigation is carried out, medium-term mortality rates remain high, as root systems developed under irrigation conditions present superficial growth being more vulnerable to drought episodes. One of the current initiatives to address this problem is the so-called "Cocoon". It is a $100 \%$ biodegradable device, built with recycled plant fibers. It is designed to reduce water stress for the planted seedlings during the first drought season, while also encouraging the development of a deep root system. This device has been successfully implemented in various countries around the world and in a wide range of different environmental conditions and objectives, from the restoration of areas affected by desertification to the recovery of agricultural uses in abandoned lands. Results after first summer drought demonstrate that Cocoon ecotechnology is working well, improving survival ratios and physiological state of the seedlings, despite its efficacy depends on the species and the environmental conditions of the site. Moreover, Cocoon is acting as refuge for some insects and could favor the growing of some commercially interesting fungi. In general, the perception of the agricultural and forestry owners, and the administrations involved, is very positive.
\end{abstract}

Keywords: arid and semi-arid ecosystems, climate change adaptation, afforestation, seedling establishment, summer drought

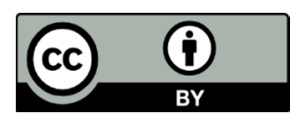

(C) 2019 by the authors. Licensee MDPI, Basel, Switzerland. This article is an open access article distributed under the terms and conditions of the Creative Commons Attribution (CC BY) license (http://creativecommons.org/licenses/by/4.0/). 